\title{
Anscombe on Expression of Intention
}

\section{Citation}

Moran, Richard, and Martin Stone. 2009. Anscombe on expression of intention. In New essays on the explanation of action, ed. Constantine Sandis, 132-168. Houndmills, Basingstoke, Hampshire: Palgrave Macmillan.

\section{Published Version}

http://www.palgrave.com/products/title.aspx?PID=279045

\section{Permanent link}

http://nrs.harvard.edu/urn-3:HUL.InstRepos:3638351

\section{Terms of Use}

This article was downloaded from Harvard University's DASH repository, and is made available under the terms and conditions applicable to Other Posted Material, as set forth at http:// nrs.harvard.edu/urn-3:HUL.InstRepos:dash.current.terms-of-use\#LAA

\section{Share Your Story}

The Harvard community has made this article openly available.

Please share how this access benefits you. Submit a story.

Accessibility 
9/10/2007 5:11 PM: ExpressIntention21.doc

DRAFT: Not for quotation, etc.

Richard Moran, Dept of Philosophy, Harvard University

Martin Stone, Cardozo Law School and The New School Graduate Faculty

\section{Anscombe on Expression of Intention}

Of course in every act of this kind, there remains the possibility of putting this act into question - insofar as it refers to more distant, more essential ends.... For example the sentence which I write is the meaning of the letters I trace, but the whole work I wish to produce is the meaning of the sentence. And this work is a possibility in connection with which I can feel anguish; it is truly my possibility...tomorrow in relation to it my freedom can exercise its nihilating power.

-Sartre, Being and Nothingness, p. 74

There might be a verb with the meaning: to formulate one's intention in words or other signs, out loud or in one's thoughts. This verb would not be equivalent in meaning to our "intend."

There might be a verb with the meaning: to act according to intention; and this would also not mean the same as "to intend."

Yet another might mean: to brood over an intention; or to turn it over and over in one's head.

Wittgenstein, Remarks on Philosophical Psychology I, 830

\section{The Problem}

Anscombe begins her monograph Intention by recalling three familiar contexts in which, as she says, we "employ a concept of intention" $(\S 1)$ :

(Case 1) Someone says "I'm going to walk to the store": An expression of intention, we might say.

(Case 2) Someone is walking (or has walked) to the store: an intentional action.

(Case 3) "Why are you walking to the store?" - "To get some milk": The question seeks - and the answer provides - the intention with which something is done. ${ }^{1}$

This isn't philosophy yet, only its raw material. Anscombe will shortly suggest the need for a philosophical investigation by suggesting that we have trouble seeing how it is one concept of intention which finds application in these cases. ${ }^{2}$ This set-up seems straightforward, yet on closer inspection someone might understandably object: "What an odd mix of cases!" The first 
case is a type of act (viz., one of speaking), and, as such, an instance of the second. Doubtless, when performed, it is also done with some further intention (case 3). So there is overlap here. But apart from this, it might be wondered: Why should expression of intention appear in an initial division of the subject at all? Sure, we put "a concept of intention" to work in this context. But we put "a concept of emotion" to work in speaking of someone's expressing emotion; and that seems unlikely - save in a world described by Borges - to head the opening divisions in a book called "Emotion."

In general, that "expressions of $\varnothing$ " will be pertinent in studying a psychological concept $\varnothing$ isn't simply to be taken for granted. Exceptions would include those concepts taken up in performative verbs, where (e.g.) to command or promise is to formulate something in words, to give it expression. But that to intend isn't a performative is seen among other ways in this, that we can speak of expressions of it, though not of a command ${ }^{3}$; and from this point of view, it seems doubtful that "expressing an intention" has any greater claim to pertinence than, say, "brooding over an intention" or "concealing an intention," and so on. Yet this is Anscombe's first sentence: "Very often, when a man says 'I am going to do such-and-such,' we should say that this was an expression of intention" (p. 1). Anscombe does not pause here to explain why she draws attention to 'expression', but instead turns to distinguishing two different uses to which (e.g.) "I am going to fail in this exam" might be put - either (1) an expression of intention, or (2) the speaker's estimate of her chances, a prediction. (p. 2)

Distinguishing expressions of intention from predictions suggests that the two were liable to be confused. So it is in fact a particular sort of 'expression' which comes up here, a verbal statement of fact. To explain, we express ourselves, and our states and attitudes express themselves, in a variety of ways -- through what we do and say, and through how we do these things. Since we are thus bound to be expressing things continuously, a central distinction in this area will be between expression in the impersonal sense (the manifestation of some state or condition) and expression in the personal sense (the intentional act of one person directed to another). ${ }^{4}$ Evidently, Anscombe is thinking of the personal sense, for her examples are all imperfect statements of fact ("I'm going to...") ${ }^{5}$ - items which can do double duty for predictions -- notwithstanding that intentions are, it would seem, expressed in other ways as well. "It would seem": In fact, in a passage occurring just after the opening, Anscombe will be found denying that intentions, in contrast to other states of the person, are ever impersonally expressed. (p.5) (The meaning of this strange and unintuitive doctrine will occupy us in much of this paper.)

To say that Anscombe has inherited this focus on "expression" from Wittgenstein, though correct, is obviously not the sort of explanation needed here. ${ }^{6}$ And in truth, if the idea were merely to locate the topic of intention by remembering some main uses of "intention," something seems forced here. For we don't really "very often" speak of "expression of intention" in characterizing what people say. Philosophical purposes aside, we don't generally speak this way unless the context gives special consequence to the distinction between the two kinds of expression -- e.g., in the law, which sometimes asks whether an intention (e.g., to take 
possession) has been expressed (the personal sense), and not merely whether it was evident under the circumstances to others.

What, then, is the meaning of Anscombe's initial emphasis on 'expression'? We aim to show the work this notion is performing throughout Intention. But the background to this task is that Anscombe's first division - expression of intention - seems incongruous. It seems to belong only to a very different catalogue of divisions, one featuring such items as symptoms or indications of intention, or intentions which are disguised or merely passively revealed; or perhaps in a catalogue of speech-acts -- expressions of belief, predictions, commands, promises, etc.

Consider now that rather strange and unintutive passage. "Expression" recurs emphatically here, in the form of a claim made by Anscombe, that while non-human animals (brutes) have intentions, they don't express them:

Intention appears to be something that we can express, but which brutes (which, e.g., do not give orders) can have, though lacking any distinct expression of intention. For a cat's movements in stalking a bird are hardly to be called an expression of intention. One might as well call a car's stalling the expression of its being about to stop. Intention is unlike emotion in this respect, that the expression of it is purely conventional; we might say linguistic if we will allow certain bodily movements with a conventional meaning to be included in language. Wittgenstein seems to me to have gone wrong in speaking of the 'natural expression of an intention' (Philosophical Investigations (§ 647) (p. 5).

Someone might read past this unhindered, because they might understandably take Anscombe's point to be merely the anodyne one that brutes do not tell us of their intentions (i.e., express them in the personal sense). But that can't be her point. For clearly what this passage is after is a contrast between intentions and states of emotion with respect to their possibilities of expression ("Intention is unlike emotion in this respect..."). That anodyne rendering would undo the contrast. For the natural behavior of brutes does express emotion (or so Anscombe allows), yet brutes do not tell us of their emotions either. So Anscombe's point is best represented -- as she herself represents it -- like this: There is no such thing as the natural expression of intention, as there is of emotion; the expression of intention is always conventional or linguistic. First appearances notwithstanding, this is not essentially -- but only by application -- a point about non-human animals. Anscombe might also have said (she should be committed to saying), "The natural behaviour of human beings is no 'expression' of their intention as well." But the question is, why not? Why say this? The problem which emerges here, beyond Anscombe's making "expressions" one of the topic's divisions, is what the relevant notion of "expression" might be, such that it has no application to the intentions manifested by an agent's stalking movements, while still finding purchase on the non-verbal manifestations of other states like emotion. $^{7}$

The solution to both problems involves seeing Anscombe's emphasis on "expression" -and more generally her explanation of intention "in terms of language" (p. 86) -- as part of a 
distinctive strategy for elucidating the unity of the uses of intention. We'll call this strategy one of immediate elucidation, and we'll contrast it with "connective strategies". An immediate elucidation exhibits the divisions of intention as inflections of a single form. It thereby also helps reveal how the unity of "intention" has become linguistically submerged, hence lost to a philosophically unassisted view. To explain this, however, it seems best to begin by recalling the shape of a prominent strand in contemporary, post-Anscombian philosophy of action, since connective strategies appear to be the main ones, or the only ones, imagined there.

\section{Background: The Transformation of Intention}

A familiar homage says that many action theorists follow Anscombe at least in (1) associating acting intentionally with acting for reasons, (2) treating the topic of intention as comprised of this and at least two other divisions (intending to act and 'intention with which'), and (3) requiring philosophy to explain how these notions are connected. This account of the influence of Anscombe's work is only roughly correct, however. A sign of inexactness is just the way her first division (expression of intention) is apt to be remembered - as e.g., here, by Davidson, in recounting his own theory:

[Earlier] I believed that of the three main uses of the concept of intention distinguished by Anscombe (acting with an intention, acting intentionally, and intending to act), the first was the most basic. Acting intentionally, I argued... was just acting with some intention. That left intending, which I somehow thought would be simple to understand in terms of the others. I was wrong. When I finally came to work on it, I found it the hardest of the three; contrary to my original view, it came to seem the basic notion on which the others depend; and what progress I made with it partially undermined an important theme...- that "the intention with which the action was done" does not refer to an entity or state of any kind. ${ }^{8}$

Loosing reference to "expression," Anscombe's first division has become "intending to act" -- a hard notion for action theory, as Davidson avers, partly because, being potentially free of any contamination by action, it seems to refer to an as yet unanalyzed state of mind. Moreover, given the general drift here - an organization of "intention" around a distinction between worldly events and autonomous mental states -- one might understandably speak of just two main Anscombian divisions. Thus, Michael Bratman:

[W]e use the notion of intention to characterize both people's actions and their minds....[O]ur common sense psychological scheme admits of intentions as states of mind; and it also allows us to characterize actions as done intentionally, or with a certain intention. A theory of intention must address both kinds of phenomena and explain how they are related. A natural approach, the one I will be taking here, is to begin with the state of intending to act.... Instead of beginning with the state of intending to act [some theorists] turn immediately to intention as it appears in action: [they] turn directly to acting intentionally and acting with a 
certain intention....This is, for example, the strategy followed by Elizabeth Anscombe in her ground-breaking monograph, Intention. ${ }^{9}$

On this reception of Anscombe, the question naturally arises: Which is the more "basic" notion of intention? For Bratman, as for Davidson, it is "intending to act," though in analyzing this state Bratman goes boldly (where Davidson had gone only reluctantly) beyond mere "desire" and "belief" to a much richer psychology of states, one more adequate to the complexities of action. ${ }^{10}$ The significance of this development will come in for interpretation later on. ${ }^{11}$ What matters for the moment, however, are only two apparent commonplaces heard in these passages: first, that "intending to act" is some state of mind; and second, that action theory should explain how this state is related to "intentional" as it characterizes things in the "world" -- what people do or cause to happen. We call the framework comprised by these points Transformed Anscombe (TA).

The steps leading from Anscombe to TA might be thought of as follows:

1. Noting that Anscombe sometimes calls her first division "expression of intention for the future", and sensing perhaps that the invocation of "expression" is not essential here, the later term is (understandably) factored-out, leaving "intention for the future" ("priorintention" or "intending to act") as the item Anscombe meant to distinguish. ${ }^{12}$

2. This effect of this - and perhaps one of its motivations too - is to give the list a new sharpness. For occupants of the new category - e.g., someone's intention to fly to Boston next week - seem, as such, to be neither intentional acts nor (supposing the agent hasn't yet done anything to realize her intention) any intention in acting. Naturally, such an intention may be taken up - or become present in some way - in her flying to Boston, and in the intention with which she does other things, like packing her suitcase. ${ }^{13}$ But it need not be. For she may change her mind, or something may interrupt her plans, and then her intention to fly to Boston will remain "pure."

3. Given the possibility of "pure" intending, it becomes hard to see how this category could fail to designate a mental state, attitude or disposition of some kind. ${ }^{14}$ So the divisions of "intention" now take shape around the philosophical polestar of the division between mind and world: two notions of intention find purchase only where there is behavior causing things to happen; a third refers to a mental state, attitude or disposition which, though in some way present in such behavior, is also abstractable from it and capable of existing on its own.

4. The theoretical elucidation of "intention" is now apt to be organized around two tasks: (1) an analysis of "intention," conceived as a (potentially "pure") mental state or attitude, and (2) an explanation of the other behavior-dependant applications of "intention" in terms of (1). Theorists are of course apt to disagree about how to carry out these tasks: What other mental states or attitudes are entailed by intention, whether some reduction ontological or otherwise -- is possible, and the relation between the relevant state of intending and intentional action, are familiar points of controversy. 
5. Generally, in TA: (A) An event is an action when it is intentional under some description; (B) an action meets this requirement when it is done for reasons; (C) this means it is susceptible to a form of rationalization (a special sense of "He did it because....); and (D) such rationalizations elucidate action through a movement from inner to outer: from the agent's beliefs, desires or other states to something happening outside him. (Whether either such a movement or its explanation is - in some previously recognized sense - a causal one, is another hub of controversy.)

From within this framework, what differentiates Anscombe is commonly thought to be the "methodological priority" she gives to intention as it appears in action and - curiously, as she doesn't discuss this - her denying that the relation between the mind and action sides of the rationalizing "because" is a causal one. ${ }^{15}$ Bratman in fact portrays Anscombe as accepting everything in (5), with one qualification: Her view of whether "intending" is an independent psychological state (not reducible to appropriate desires and beliefs) cannot be made out because she says too little about this state. ${ }^{16}$

This story of progress within a single framework of action theory has its obvious satisfactions. Nonetheless, a distortion is present when the contemporary theorist credits Anscombe with having discerned the starting points of TA, as described here. This comes out in the following puzzle: While Anscombe does contemplate intending in its putatively "pure" or unworldly form -

[A] man can form an intention which he then does nothing to carry out, either because he is prevented or because he changes his mind: but the intention itself can be complete, although it remains a purely interior thing (p. 9)

-- she offers, as Bratman observes, almost no account of it. In fact, returning late in the book to her first division, Anscombe merely remarks briefly that what has been "said about intention in acting applies also to intention in a proposed action" (p. 90). Here a large gap in her account must appear from the contemporary point of view: How can her previous teachings about intentional actions, things done, simply now "apply" to an intention in a proposed action, conceived as something which may remain "a purely interior thing"?

By TA's lights, Anscombe's previous remarks cover 5A-D. Beyond identifying the central case of intentional action with action for a reason, they explain how when an agent so acts he has a further intention, which often furnishes a wider description of what he is doing and related matters. But surely some further explanation of "intention in a proposed action" and not merely an application of these doctrines - was needed, even by Anscombe's standard of compression. For we can't understand, say, "an agents intention to fly to Boston next week" merely on the anemic basis of an agent's having a reason to do as much, however this notion is analyzed. ${ }^{17}$ Among the problems, there is the common fact that the agent may simultaneously have a reason not to fly to Boston without it being the case that she both intends to fly to Boston and intends not to. Intentions apparently stand open to contradiction in a way which mere 
reasons do not. Since what has been said about intention "in action" thus seems insufficient to cope with intention "in a proposed action," the question arises: Having distinguished these notions of intention, why would Anscombe omit any significant analysis of the latter?

Two answers appear in the literature. First, no reason: Anscombe simply omits to discuss intending, leaving it to us. This seems implausible: One should really choose between making Anscombe the founder of the Three Divisions and having her omit to discuss the first -the combination amounts to philosophical malpractice. Second, her reason is behaviourist: She thinks we will grasp how to explain intending as some function or complication of intentional action, which she takes to be more basic. This too is implausible: And are we really to suppose that Anscombe (a student of St. Thomas, after all) seeks, with the behaviorist, to solve intellectual problems by collapsing spirit into nature?

Significant internal difficulties block the attribution of behaviourism, in any case. Anscombe's forthright talk of intention as "a purely interior thing" is one difficulty. Her pivotal remark that what was said about intention in acting "applies also to intention in a proposed action" is an even greater one. For a genuine behaviourist doesn't talk that way. He doesn't say that his account of (e.g.) pain-behavior applies also to pain! The words "applies also" evidently say that a distinctive kind of unity is available here: that which consists in seeing a group of items as falling under - or engaging application of - a single idea, form or pattern. In contrast, what the behaviourist needs to say at this point is that the relevant mind-characterizing notions can be analyzed or explained in terms of other items. Otherwise put, the behaviourist is someone trafficking in the divisions emerging from TA. His problem is therefore to connect the different notions of "intention" through a strategy of explanatory extension; and, in this at least, he will differ from other contemporary theorists only in taking for secondary those notions which they take for basic. But in whichever direction it runs, such a connective explanation will be something different from what Anscombe appears to contemplate: an apprehension of the divisions of intention as instances of a single form. ${ }^{18}$

This explains why the best evidence of behaviorist sympathies in Intention is bound to be inconclusive. For the best (of the thin) evidence must be what Anscombe says just after mentioning the possibility of pure intention:

[T] his conspires to make us think that if we want to know a man's intentions it is into the contents of his mind, and only into these, that we must enquire; and hence, that if we wish to understand what intention is, we must be investigating something whose existence is purely in the sphere of the mind; and that although intention issues in actions, and the way this happens also presents interesting questions, still what physically takes place, i.e., what a man actually does, is the very last thing we need consider in our enquiry. Whereas I wish to say that it is the first. (p. 9)

"Some say A then B, but I say first B then A." No doubt, there is a genuine issue of starting points here, of what is to be modeled on what. Anscombe's remark will suggest behaviorism, however, only to someone already sure of the theoretical options: Either the application of 
"intention" to what people do will have to be explained in terms of its use to characterize a state of mind, or vice versa. There is another possibility, however. Say that Anscombe's aim is to exhibit the unity of intention directly, by subsuming the three divisions under a single form. Once properly in view, it should be possible to see what this form applies to, without further complication. On this reading, "First B..." says only that one doesn't come to see what formally unites the "interior thing" with "intention in acting" by asking first what properties characterize someone's psychological state as one of intending; it is rather in action that the genus comes most perspicuously into view. While this might prove an unsatisfying thesis about intention, it isn't exactly novel to suggest that members of a kind have asymmetrical powers of exhibiting it. If you want to see why bad arguments are arguments, for example, it is best to start by examining the valid kind, this being more basic. Or, again, successfully murdering is more basic than attempting the same. To see what kind of wrongdoing unites these, it seems best to start with the infringement of someone's right in the completed act; and from here, one can discern the wrong in the more attenuated case, without the aid of the sort of theories which would have to say (starting at the other end) that, e.g., the wrong in every act of murder is "really" only that of someone's intention to murder, plus some causal assistance from the world. Similarly, on the present thesis, what kind of entity or state this is - intending to write the word "action" - will best be exhibited in the performance of writing the word "action." 19 This needn't incur any commitment to the behaviourist's denials.

In support of this: Anscombe speaks of "intention in a proposed action" (where TA is apt to write "intending" or "future-directed intention"). Her point is that the distinction in question here is one between two intentions in action -- items sharing an underlying structure or form, but differing in their positions along a spectrum of presence. On this view, a future intention to write the word action, is structurally, a variant of writing the word the action; it is distinguished only by its remoteness, by the intended intervention being, as it were, not-yet present. This will need further development: Just what Anscombe takes this common structure or form to be -- the one best exhibited by intention in present action -- remains to be articulated. But it shouldn't be difficult to guess that the answer will have something to do with the attention she gives to her special question 'Why?' This is evidently the central "device" (p. 80) in her 'non-connective' explanation of the unity of intention. It also goes hand-in-hand, as will become plain, with her emphasis on "expression of intention."

Here, however, we reach ahead. To summarize, the divisions of 'intention' being connected in TA aren't, on their face, Anscombe's divisions. One can of course ask why Anscombe omits to discuss intending, and offers little analysis of this putative state at just the point - intention in a proposed action - where analysis seems needed. But this problem might also be turned around. Despite the standard homage, few theorists actually find much use for Anscombe's first heading, at least as she inscribes it. Reading them, one would never suspect that "expression of intention" figured centrally in her discussion.

\section{Why "Expression”: Three Clues}


Turning back to the problem of the prominence of 'expression' in Anscombe's initial setup, we find two explicit clues in Intention: (1) Ignoring the expression of intention in favor of what it is an expression of is apt to lead to wrong notions:

e.g., psychological jargon about 'drives' and 'sets'; reduction of intention to a species of desire, i.e, a kind of emotion; or irreducible intuition of the meaning of 'I intend'" (pp. 5-6).

And (2), it is also apt to obscure just how different expressions of intention are from paradigm cases of expressions of states of mind.

(1) Anscombe's reference to Wittgenstein's discussion of "I was going to...." - a "pure" intention again, only the time for action is past - pinpoints at least one "wrong notion": viz., that the truth or assertability of "I'm going [was going] to $\varphi$ " consists in some occurrent words, images, sensations, or feelings. ${ }^{20}$ Against this: A person's emotions, desires or drives may lead in contrary directions without hint of irrationality; not so their intentions. In addition, one can have an intention over a period of time (e.g., to see a friend) while seldom thinking of it; and, in recalling an intention, whatever "scanty" mental items memory presents as having occurred "do not add up to" - they aren't necessary or sufficient for - having that intention. (Nonetheless one can easily enough recall what one was going to do - one simply gives the words which express it.) ${ }^{21}$ All this suggests that (unlike, e.g., "I have an itch" or "It feels like going down in a lift"), "I intend to..." neither reports an experience-content nor requires an experiential vehicle. To adapt a remark of Anscombe's adapting a remark of Wittgenstein's: No experience could be an intention, because no experience could have the consequences of intending. $^{22}$

(2) Considering such paradigm cases of the "expression" of an experience or state as "Ouch!," "I'm in pain," or "Foiled again!," it might be said: Someone who tells us what they are going to do isn't in that way "expressing" an intention; they aren't simply venting. Indeed, "I'm going for a walk" no more looks like a communication about the speaker's inner state than does, say, her belief that the store closes at 8:00, as expressed by means of an appropriate declarative sentence. Only in special cases does an expression of belief aim to inform us about the speaker -- i.e., when it is about her. So too, when someone (actively) expresses an intention, Anscombe says, they give us information -right or wrong -- about what is going to happen. (Of course, biographical facts will get passively expressed or manifested as well.) Herein lies one point of likeness with predictions: An expression of intention such as "I'm going for a walk" is true or false according to whether the speaker goes for a walk. ${ }^{23}$ Hence, like a prediction, it can serve to give someone direct knowledge of what is going to happen. ${ }^{24}$ It is not a mere indication of the speaker's psychic condition.

These considerations - in brief, the dissimilarity of intention to a psychic state on the model of emotion -- do suggest some motivation for Anscombe's emphasis on "expression." For 
a personal "expression of intention" clearly makes a kind of claim, and has consequences, recognition of which will serve to place intention outside this model. But without more, these points suggest that Anscombe's peculiar emphasis might be only a dispensable device for avoiding certain philosophical errors -- "particular dead-ends," as she calls them (p. 6). To see why these points don't go far enough, remember that the personal expression of belief is also to be understood as presenting a proposition of fact (an answer to the question "What did he/you say?"); it too is no mere indication of mental goings-ons. Yet, presumably, this isn't likely to suggest that "expressions" will be a main division in studying belief; that wrong notion, should it arise, could simply be dealt with directly. Why then - apart from the pro-active avoidance of errors - should "expressions" figure as one of the main divisions of the topic of intention? That was the problem $(\S 1)$, and the problem remains.

The main clue needed here must evidently concern features of intention which are special to it, and which therefore generate a special problem. And there is such a clue, in the low-level linguistic facts which suggest divisions of the topic in the first place. What matters most is just that applications of "intention" are spread along a spectrum extending from what is, naively speaking, "in the mind" to what is "in the world." Picturing a line, on the far left will be found pure intentions, defined as cases in which the agent intends to do something but hasn't yet done anything else in order to do that. Moving rightward, the agent has more worldly deeds to show for his intentions: If he is described as $\varnothing$-ing or as intending to $\varnothing$, then, at this point, it will be correct to say that he is also doing various things in order to $\varnothing$, or because he intends (wants, aims) to $\varnothing$. At the far right, his performance is fully unfolded and finds description in the past tense: "He Ø-ed" (or "He has Ø-ed") will now be true, and not merely - what holds anywhere between these end points - "He was Ø-ing." The special problem, as all agree, is that of exhibiting the unity of the notions of intention which appear here.

This progressive structure has no parallel in the case of emotions, desires or beliefs. Generalizing this contrast, we may say: It begins to specify what is meant by a "state" to note that the progressive form of the relevant verb - e.g., "to believe," "to be hungry," "to be taller than" - isn't used. To join a subject to such a verb, no grammatical discriminations of progressive vs. perfected aspect ("was $\varnothing$-ing" vs. " $\varnothing$-ed") are needed, only those of tense; and there is always a good inference from the present ("X is hungry...") to the perfect ("X was hungry..." said at some future time). States, in short, are static; and this exhibits, by way of contrast, two related features of the spectrum of uses of intention.

First, with anything an agent does, there are, in principle, any number of purposive subparts - things he must do in order to do that - and this is because his performance takes time: ${ }^{25}$ It may be done quickly (taking little time) or slowly, and we can mark its progress - and thereby distinguish further points in our spectrum - by speaking of someone's "just starting to $\varnothing$," "being nearly half-way done," "just finishing up," and so on. Performances unfold: They involve a diminishing future and a swelling past, of what the agent needs to do in order to do, or have done, what he is doing. States, in contrast, merely go on for a time, without unfolding: E.g, no one will be found slowly desiring a drink, or almost finished being the tallest boy scout - even if his desire is soon to be quenched, or others are about to grow. ${ }^{26}$ 
Second, the intentional object of "He intends..." is given by a performance verb ("to Ø"), so that if someone intends to $\varnothing$, then what fits this notional "state" of his is another performance to which the spectrum of the concept of intention in principle applies (viz., his Ø-ing, or his Z-ing in order to Ø), and not, apart from this, any extensionally equivalent state of the world. Hence the object of the attitude of intention is another intention or a performance, whereas what makes a belief true (or satisfies a desire) can be propositionally rendered, and is only in special cases characterizable through another application of these same concepts: Not all beliefs are about other beliefs, as not all desires could be merely for other desires. And whatever their causal contribution to a particular action, beliefs and desires do not come to serve as qualifications of the action itself (e.g., as 'beliefish' or 'desireous').

Here, then, it looks as if "intention" earns its literal, archaic sense - a "stretching forward" - for it is structured as action itself is. Not that this is surprising: It is location on a spectrum of unfolding action which fits an event to be described using concepts of intention in the first place; ${ }^{27}$ the kind of thing an intention is to be explained in terms of a concept which applies throughout the spectrum. Anything this wasn't true of - which didn't characterize both a person's attitude as well as the object of that attitude -- wouldn't be our (i.e., a) concept of intention. Anscombe asks:

Would intentional actions still have the characteristic 'intentional', if there were no such thing as expression of intention for the future, or as further intention in acting? I.e. is 'intentional' a characteristic of the actions that have it, which is formally independent of those other occurrences of the concept of intention? (p. 30) ${ }^{28}$

And she answers: "This supposition [that intention only occurred as it occurs in 'intentionalaction']...carries a suggestion that 'intentional action' means as it were 'intentious action'...that an action's being intentional is rather like a facial expression's being sad." This remark traces the consequences of losing the unity of the concept of intention across its different contexts: Cut "intention" loose from its unfolding on a spectrum, consider it only as a qualification of action, and "intentional" becomes "intentious," essentially the name of a state, like sad or angry. By the same token, if TA has recently tended to discover that an adequate account of action must go beyond states of "having reasons" conceived as propositional belief-desire pairs, what it has caught sight of may be structurally expressed like this: No psychology will afford the right materials for explaining action which does not make use of a concept which applies throughout the spectrum of unfolding action, and which thus has same internal complexity as actions themselves.

This said, the image of a performance as a line touching points of "pure" and "perfected" intention is to be taken with a grain a salt. What is represented here is not a performance, but only the kind of thing a performance is, its structural possibilities. A few disclaimers will help to bring the spectrum into clearer focus:

- First, no implication arises that every action touches the right-most point. To the contrary, as J. L. Austin has observed, a mark of any action is its exposure to the risk of failure or 
incompleteness. $^{29}$ No inference is available from the progressive ("He is Ø-ing") to the perfect ("He Ø-ed").

- Likewise, no implication arises that every action begins at the left-most point. Not all intentional action is the execution of a prior intention. Many intentions -- e.g., rolling out of bed in the morning, changing speed according to traffic -- never exist apart from the things one does.

- Third, where there are pure intentions: No implication arises that they precede acting, except relative to some descriptions of the action in question. To illustrate, someone may have now a pure intention to build a tree-house, but only - as is likely - because he is already underway with something else of which building a tree-house is a part or phase: e.g., he is raising his kids to enjoy the outdoors, or improving the property before he sells it so he can retire and finish writing his novel.

- Likewise, no implication arises that in achieving the right-most point, there remains nothing virtual or pure about what the agent is doing. To illustrate, even after our agent's intention to build a tree-house has become impure, the point arrives where he forms (what is now) a pure intention to buy lumber; failure on this score will mean he never builds a tree house, and perhaps never does the things of which this was a part.

- From the above, it appears that wherever "purity," as defined here, is used to characterize intentions, it must be possible to apply the term in the same sense to actions themselves. Consider how it is with our agent who, far along in building his tree house, forms an intention to drive in a nail to fasten two boards together. At the moment, his intention is a "pure" one, for he has taken a break and lies on the grass. What is this agent, with his nail- and plankregarding intentions, now doing? Well, among other things, it would be correct to say he is building a tree house (he has been at it since winter), only, at the moment, this action of his remains pure, for he is not now doing anything in order to do that. Any action of significant duration is apt to have moments of pure intending and pure acting among its innumerable parts.

Notice that our agent's nail-regarding intention may at present be pure (just like his action of building a tree house), though his intention to fix together two boards is impure (he has placed them next to each other) - all this, notwithstanding that hammering the nail, fixing the boards, and building a tree house are, as Anscombe teaches, the same action under different descriptions. So although pure intending comprises the left-limit case, and perfected action the right-limit one, this does not entail that what the person purely intends to do isn't, under a wider description, an action which is already underway and uncertain of completion. Davidson's own example of a pure intention - writing the word "action" - illustrates the point: I have formed this intention because I'm already engaged in writing a sentence, and this with a view to writing a book, the second in a series, and so on. Further, once we are able to locate impure intentions in this way by enlarging the frame of pure ones - it should naturally be possible also to find pure ones within impure ones, for the principle is the same. ${ }^{30}$ If there is a tendency to think of action in terms of a one-way sequence, beginning with intending and moving through acting to having acted - i.e., as something beginning in the mind and ending in a state of the world - an illusion is present which 
perhaps arises from the philosopher's focus on unmotivated or point-like actions (the lifting of a finger) strangely abstracted from the vita activa.

Now, returning to the question of Anscombe' divisions, we venture the following thesis. What makes the phrase "expression of intention" look like an outlier in her list - its reference to speech - is also what allows it to stand as a natural example of each division, and thus, in a sense, to subsume the entire list:

(Case 1) Someone says "I'm buying some shoes": An expression of intention for the future (perhaps even a pure one).

(Case 2) Someone says "I'm buying some shoes": An intentional act (e.g., when the speaker is asked what he is doing).

(Case 3) Someone says "I'm buying some shoes": A further intention in acting (e.g., when this is the answer to the question "Why are you walking out the door?")

Not that this is unexpected, as if "expression of intention" should somehow be proprietary to the special case of pure intending. The spectrum of intention -- which exhibits that as a limit case already suggests this wouldn't be so. And consider the linguistic facts: One who offers, e.g., "I intend to take the train to Boston tomorrow" (a pure intention, let us suppose) might also express themselves thus: "I am taking the train to Boston - tomorrow." And having begun to pack, they might explain what they are doing by reference to the partial presence of that larger performance - "I'm taking the train to Boston" - but they might also revert to the notionally "psychic" explanation: "I intend to take the train to Boston." If any of these are "expressions of intention," surely all must be.

The principle of this linguistic sharing of labor is seen, according to Anscombe, when the use of the progressive is denied:

[T] he less normal it would be to take the achievement of the objective as a matter of course, the more the objective gets expressed only by 'in order to' E.g., "I am going to London in order to make my uncle change his will'; not 'I am making my uncle change his will.' (p. 40)

Likewise, the less normal it would be to take the achievement as a matter of course, the more the objective ("in order to Ø") gets expressed with "because" followed by a proposition which couples the performance verb (to Ø) with some overtly psychic form ('I intend ...' I want .." "I plan...", etc.): "I am going to London because I intend [want, will try, etc.] to make my uncle change his will." Where ordinary language demands them, such "psychic" expressions are markers of absence or remoteness in an unfolding performance. But in this, they are exactly like the idiomatic use of the simple progressive ("I am Ø-ing"), which itself always conveys imperfect aspect, incompleteness and the risk of failure (only to a different degree). All expressions of intention, then, are such as to explain action by locating it within a larger action- 
in-progress. Where "psychic" markers of remoteness are available, however, we can expect the use of the simple progressive to be correspondingly confined to a narrower range of cases exhibiting relative presence or proximity. ${ }^{31}$

This explains a critical remark of Anscombe's. After (1) connecting the notion of intentional action to the applicability of a special question 'Why?', and (2) showing how an answer can furnish terms for a wider description of what an agent is doing (i.e., just when the question has the right sense), and (3) noting that this leads, chain-wise and eventually, to "a break," to an act-description characterisable, on account of remoteness, only as something the agent is now going (or - we may add - intending, wanting, planning, etc.) to do, she writes:

I do not think it is a quite sharp break. E.g., is there much to choose [i.e., in answer to why someone is putting on the kettle] between 'She is making tea' and 'She is putting on the kettle in order to make tea [and, we may add, "She intends to make tea"? - our note] - i.e., 'She is going to make tea'? Obviously not. (p. 40).

The implication of this is that the notionally mind-characterizing uses of intention differ from the others only in articulating a greater degree of remoteness or uncertainty. That is, they continue at a different point in the spectrum - the same form of explanation which was most perspicuously seen in the earlier links of the chain: essentially, the fitting of an action into a larger, presently incomplete whole. Call this the teleological structure of action: Action is the kind of thing which rationalizes its sub-parts (those actions done "in order to" do it). As Michael Thompson has argued, this suggests that it is fundamentally intentional actions-in-progress which explain actions, and that it is only on the basis of this primitive structure - an action as a space of reasons - that a more sophisticated development becomes possible: viz., the joining of a psychic expression with a performance verb to create an etiolated form of the same structure in the interest of articulating relative non-presence, remoteness or uncertainty. ${ }^{32}$

In support of this, it bears remembering that the psychological items under consideration are someone's intending, planning or wanting to do something (to Ø) and not, say, someone's wanting or desiring that something or other happen or be the case. The progress noted earlier in TA toward more committed or articulated psychological states (beyond belief and desire) was just the recognition that only states of mind having a role in the unfolding of action itself - which means only 'states' subject to qualification (i.e., to placement on the spectrum) as "pure/impure" - can effectively explain action by reference to the agent's attitudes. ${ }^{33}$ But this just means that such states - intending to _, planning to__, etc. -- inherit through their objects (a performanceform: to $\varnothing$ ) the distinctive teleological structure characteristic of intentional action. And this suggests that no matter how rich a psychology we employ, we do not attain to an understanding of the behavior-characterizing uses of "intention" on the basis of relation to a psychological state, except by helping ourselves to a notion of a 'state' informed by a prior understanding of the concept of intentional action (as in intending or planning to do something). 
To summarize: "I intend (plan, want, etc.) want to make tea" expresses the same incompleteness of action seen - at earlier points in the chain of answers, where achievement is more "a matter of course" - in the use of a performance verb by itself: E.g., "Why are you boiling water?" -"I'm making tea." "And why are you making tea?" -“I intend to serve the guests." Hence all such psychic forms are performance modifiers: Insofar as they are employable in action-explaining answers to the question "Why?," they express forms of being on-the-way-to-but not-yet having Ø-ed, of already stretching oneself toward this end. So expressions of intention "for the future" are variations on a common theme: They are structurally of a piece with the simple progressive, only further to the left on the spectrum, where they permit a more refined articulation of the imperfection - an agent's being commitedly underway - informing all action explanation. In expressing imperfection, they are just like any other suitable answer to the question "Why?, whether this be a declaration of what one will do, a description of what one is currently doing, an account of the intention with which one is doing something, an explanation of what one desires or is trying to do, or - think of Anscombe's shopping list (p. 56) - a specification of what one is to do. The logical relations between these expressions of intention aren't themselves very important. As a matter of ordinary language, they admit of no exact relative placement on the spectrum, though they are of course open to the stipulations of the philosopher whose purposes require more precision.

\section{Expressions of Intention: The general and the special use}

Conceived as an answer to the question "Why?," "expression of intention" is clearly a capacious notion (any item on the spectrum can be represented as such an answer), ${ }^{34}$ and it is this capaciousness (the power to exhibit what is structurally common to any use of intention) which recommends "expression of intention" for Anscombe's purposes. On this conception, there could be no question of finding out what an expression of intention is by first investigating the properties which characterize a psychological state as one of intention, as if the powers this state might have to rationalize what someone does might then remain open for investigation. Anscombe's focus makes us take things the other way around: What can and does count as an agent's "expression of intention" is determined by its availability to enter into an elucidative account of action (fitting it into a whole-in-progress), its suitability, in other words, to be given to another who asks what is going on. An intention is whatever can be given to another in an expression suited to play this role.

The special problem addressed by this account arises from the tendency for the continuity of uses of "intention" to get disguised: "Intend" looks like a state (like "believe") and this sets the problem of its connection to "intentional" as applied to things getting done. Indeed, by at least one criterion, "to intend to $\varnothing$ " should designate a state, since an inference from the present ("He intends to Ø") to the perfect ("He intended to Ø") does hold, and since, unlike a performance, intending to $\varnothing$ does not - notwithstanding the colloquial use of the progressive take time. ${ }^{35}$ On the other hand, the fact that "intending" (like any psychic verb put to employment in explaining action) takes a performance-form rather than a proposition as its object seems to mark a decisive difference. This is related to two features of "intending" which would make it quite special among states, but which are commonplaces of performances. First, 
we can ask "why" (for what purpose, with what intention) someone intends to $\varnothing$, just as we can ask this about action itself. (All intentions are like actions in this way: they are explained by and they explain - other actions and other intentions.) Second, intending to $\varnothing$, being thus something voluntary, is subject to being commanded, like any action. ${ }^{36}$

Taking it that such differences are what matter (and not what label one applies), we propose the following account of the significance of "expression of intention" for Anscombe.

First, although Anscombe quickly leaves her first division ('expression of intention for the future') aside till later, a distinctive form of verbal exchange remains a pervasive feature of her exposition: "Why are you lying there?" --"I'm doing Yoga"; "Why did you pump water this morning?" --"To poison that lot, don't you know?"; "Why worry about them?" --"Those people have strangled the country long enough, I intend to get the good people in." All of the positive answers in such interrogations are "expressions of intention," not just the last answer (an intention for the future):

[I]f a description of some future state of affairs makes sense just by itself as an answer to the ['Why'] question, then it is an expression of intention. But there are other expressions of the intention with which a man is doing something: for example, a wider description of what he is doing. For example, someone comes into a room, sees me lying on a bed and asks 'What are you doing?' The answer 'lying on a bed' would be received with just irritation; an answer like 'Resting' or 'Doing Yoga', which would be a description of what I am doing in lying on my bed, would be an expression of intention." (pp. 34-35)

So "expression of intention for the future" is one species of a common genus, that of positive or action-elucidating answers to the special question "Why?" Recall the role of that question. It provides a definition of an "intentional act" in terms of the applicability of a question to which the agent can always give some knowledgeable response. Given this, it should be possible to see that "expression of intention" (in the wide, generic sense) works to exhibit the unity of the three, initially disparate-seeming divisions. This is just what Anscombe says:

To a certain extent the three divisions of the subject made in $\S 1$, are simply equivalent. That is to say, where the answers 'I'm going to fetch my camera' [expression of intention for the future], 'I am fetching my camera' [intentional act] and 'in order to fetch the camera' [further intention in acting] are all interchangeable as answers to the question 'Why' (p. 40). ${ }^{37}$

On this account, the unity of the divisions lies both in the applicability of the question "why" to the material of each, and in the suitability of each to itself rationalize action - i.e., to figure in an agent's answer to the question "why," asked about something else he is doing (in the present example, his going upstairs). That is, the unity of the divisions is seen in the fitness of their corresponding linguistic expressions - "I'm going to Ø," "I'm Ø-ing," “...in order to Ø " - to provide elucidatory responses in a special interrogation of the agent. 
"Expression of intention" thus finds a narrower and a broader use in Intention: narrower, as one of the headings - "expressions of intention for the future" - which brings the topic provisionally into view; more broadly, as the genus - comprised of answers to the question "Why?" - which formally unites the three divisions. This way of putting things seems to reverse Anscombe's better known formula, according to which an intentional action is one subject to the question "Why?" But the possibility of such reversal is implicit in the chainlike structure of what Anscombe calls "the ABCD form" (p. 45), whereby a positive answer to the question "Why?" is itself the description of an intentional action, and, as such, subject to that question. Starting, then, with an intentional action, we can move forward along the chain by interrogating the action -- "Why?" For just when this question has the relevant sense, positive answers to it are themselves expressions of the agent's intention. ${ }^{38}$ But, starting from the same point, we can also move backwards along the chain, by remembering that an action, suitably described, is something which can be an agent's answer to the question "Why?" (i.e., asked about something else he is doing). Anscombe's ABCD form thus pictures intentional action as both ground and grounded, explanans and explanandum, something both subject to, and responsive to, a distinctive interrogation. And this is represented by saying that the unity of the three divisions lies in their fitness to appear in "expressions of intention" in the generic sense: answers to the question "Why?"

Summarizing, Anscombe's basic idea - her general strategy for discharging the explanatory task set in $\S 1$ of Intention -- is this: (1) The applicability of the relevant question "Why" is what marks anything out as an expression of intention (p. 90); (2) any expression of intention thus subject to the question "Why" is fit also to answer a serially related question "Why"; and (3) the unity of the trinity - intention in a proposed action, intention in a present action, and intentional action - is seen in this, that each is capable of being represented in an "expression of intention," furnishing an answer to a question "Why." Thus represented (as answers in the interrogation of action), the three divisions are generally interchangeable: Usually, "there isn't much to choose between them." (p. 40)

\section{V. "In terms of language"}

At this point, a contemporary action theorist might still ask: Why define intentional action "in terms of language" (p. 86) - a chain of questions "Why?" Obviously, the content of such exchanges - e.g., "Why are you lying on the bed?" -" I'm doing Yoga" - might always be exhibited, apart from the interrogative context, in a variety of ways, e.g., "A is lying on the bed because she is doing (she intends/wants to do) Yoga." Such actions can and do take place without anyone making any speeches! ${ }^{39}$ Wouldn't it be less obscure to factor out reference to questions and answers, and speak instead of intentional action as (e.g.) "action for a reason"? "Expression of intention," in that case, needn't get any special emphasis.

One answer to this challenge lies simply in the fruitfulness of Anscombe's expository procedure in revealing unity in the otherwise diverse materials of action (cf. p. 80). Still, confidence in this procedure would improve if it became clearer how the specifically linguistic 
representation of intention really is an aspect of the thing represented. A further answer might run: "Intentions, like other conditions of the person, may intelligibly be attributed only insofar as they are publicly expressed." True enough. But Anscombe's expository procedure involves "expressions" of a quite special sort, those suited, we may now say, to be a person's answers to a question addressed to him. No one will be tempted to think of "expressions" in this sense as the only or canonical way in which various other conditions of the person get revealed. Is there a reason to think that intention is different?

Return to that strange passage concerning animals ( $\S$ I). Here Anscombe does appear to say that intention is different in this respect, and she even pauses to correct Wittgenstein on this point. Wittgenstein had written:

What is the natural expression [Ausdruck] of an intention? - Look at a cat when it stalks a bird; or a beast when it wants to escape. ((Connection with propositions about sensations.) $)^{40}$

But this "goes wrong," according to Anscombe: The expression of intention "is purely conventional" or "linguistic." Animals thus "have intentions" but, lacking language, don't express them. ${ }^{41}$ What makes this proposition strange is that while Anscombe (1) recognizes that intentions are manifest in non-verbal behavior without further gloss ${ }^{42}$; and (2) allows the term "expression" application to the natural manifestation of other states (like emotion); she nonetheless (3) challenges Wittgenstein on this point: An animal's behavior isn't any expression of its intention. Taking it that "expression of intention" is a device for exhibiting the unity of "intention", this further problem is raised here: Is there a way of seeing Anscombe's Proposition

AP: There is no such thing as the natural (only the linguistic) expression of intention as informative rather than merely stipulative? A positive answer would make clearer how the representation of intention "in linguistic terms" comes, so to speak, with the matter itself.

To begin with, however, a few words about what this question is not.

As was said, questions concerning an animal's capacities aren't essential here. We are familiar in the human case with the distinctions -- expression vs. other indications, natural vs. conventional expressions - invoked by Anscombe. Among us, there are both verbal and nonverbal expressions of fear, for instance. So if the expression of intention is purely linguistic, then it must be true of the man, and not just of the beast, that the movements of stalking a prey (or catching it and hauling it back to camp, etc.) aren't to be considered "expressions" of intention, notwithstanding that these movements make intentions manifest. Anscombe's point applies to all animals if it applies to any.

Similarly, questions concerning whether non-linguistic creatures can be credited with having with intentions at all remain bracketed here. Negative judgments might seem to support Anscombe's linguistic procedure, since they often derive from a focus on the formation of plans, 
or standing intentions - cases in which the basis for attributing intentions must go beyond natural behaviour. ${ }^{43}$ But not all intentions are standing ones or the result of making plans. And Anscombe's challenge to Wittgenstein, in any case, does not concern some purer type of standing intention, but just the immediate intentional action of the cat stalking the bird. To speak of "expression" in this case would be as inapt - she says -- as calling "a car's stalling the expression of its being about to stop." Unobvious as this thesis is, it expresses no skepticism about the car's being about to stop, or about the engine evincing this fact. Likewise, Anscombe nowhere denies (rather, she consistently asserts) that the structures of action uncovered in her investigation apply beyond the human world. (p. 86-7)

Finally, it is worth noting that Anscombe's remarks on animals run contrary to recent arguments which enlist one of her ideas - viz., that actions are intentional "under a description" in recommending the conclusion that neither intentions nor propositional attitudes are possible for creatures without a language. Davidson writes:

One can intend to bite into the apple in the hand without intending to bite into the only apple with a worm in it [...] The intensionality we make so much of in the attribution of thoughts is very hard to make much of when speech is not present. The dog, we say, knows that its master is home. But does it know that Mr. Smith (who is his master) or that the president of the bank (who is that same master), is home? We have no real idea how to settle, or make sense of, these questions. $^{44}$

The intensionality of intentions does suggest that the capacity to recognize intentions in others is exclusive to the talking creatures, or those who interpret the talk of others. But if a creature does not recognize intentions, must it therefore have none of its own ${ }^{45}$ Notably, Anscombe insists that whatever may be 'language-centered' in her account, and whatever the role of particular descriptions in delineating the intentional aspects of action, we do discern intentions in nontalking creatures:

It sounds as if the agent had a thought about a description. But now let's suppose that a bird is landing on a twig so as to peck at bird-seed, but also that the twig is smeared with bird-lime. The bird wanted to land on the twig all right, but it did not want to land on a twig smeared with bird-lime. [...] Landing on the twig was landing on bird-lime - we aren't considering two different landings. So, if we form definite descriptions, "the action (then) of landing on the twig", "the action (then) of landing on a twig with bird-lime on it", we must say they are definite descriptions satisfied by the same occurrence, which was something that the bird did, but under the one description it was intentional, under the other unintentional. That the bird is not a language-user has no bearing on this. ${ }^{46}$

We say the bird is intentionally landing on the twig (but not on the lime-twig) because we can see that 'landing on a twig to peck at bird-seed' answers to purposes the bird is assumed to have, whereas '.... a twig smeared with lime' does not, even though we are talking about one and the 
same twig. We seek a description which makes what the bird did comprehensible within what we know the bird is seeking. A reference to the agent and its good does operate as a constraint here, but this needn't be a reference to the agent's psychology narrowly conceived, i.e., to what is thought or said. Rather, we apply the descriptions under which the creature's action is intentional, without supposing that the creature has such descriptions 'in mind'.

In sum, various questions concerning the attribution of intention to animals don't shed light on Anscombe's strictures on what an expression of intention can be. What could be at stake for her in refusing to apply the innocuous-sounding phrase "the natural expression of intention" both to humans and other animals? That is the nub of the problem.

\section{What natural indications can't do: Contradiction, Commitment, Impugning the Facts}

One possibility should be ruled out. Anscombe had better not be found saying that by "expression" she simply means expression in the personal sense. From this it would of course follow that animals do not express intention, for to express intention (or anything else) you've got to use language. But this would be mere stipulation. ${ }^{47}$ Against this, let it be clear that anyone can call non-verbal manifestations of intention "expressions" if they like - what to call things isn't the question. The question is what distinction Anscombe seeks to mark by refusing application of "expression" to natural manifestations of intention. ${ }^{48}$ It looks like the answer must be: some distinction between the verbal and non-verbal manifestation of (1) intention on the one hand, and of (2) emotion (and other states) on the other. But what distinction? If a creature's stalking its pray is not to be considered an expression of intention, the interest of this thesis what raises it above empty stipulation -- must derive from a distinction we recognize here.

But there is a distinction to recognize here: Between natural behaviour which manifests intention and the overt verbal expression of intention, there exists a gap in logical powers, without parallel in the case of emotion or other states.

To explain, it seems natural to speak contrastingly of natural and conventional "expressions" of, say, fear, precisely because, in this case, conventional expression can take up or perform the same work as natural expression - there is no gap. Otherwise put, the contrast (natural/conventional) is at home within a space of common functions, where verbal expression continues (while also enhancing and rendering more precise) the same functions more primitively available by natural means. ${ }^{49}$ The other's frightened look and his "I'm afraid" can convey the same thing - his fear. This isn't to say that natural expressions of fear are given to another or meant to inform him. But conventional expressions of fear aren't always given either. $^{50}$ When they are, however - and this is what matters here - what they overtly convey is what might also be read in the speaker's non-linguistic behaviour. Verbal expressions of intention, in contrast, do not ever stand in for intentional behavior in this way. Certainly it would be wild to suggest that they are "learned as a substitute" for intentional behavior - one point subserved by the phrase "natural expression" as applied by Wittgenstein to emotions and sensations. ${ }^{51}$ And as Wittgenstein himself notes, there isn't any distinctive behavioral repertoire of intentional action, as there is of emotional states and feelings. ${ }^{52} \mathrm{No}$, the relation between verbal expressions of intention and intentional behavior is different than the relation between 
(e.g.,) verbal expressions of fear and natural fear-behaviour. It is this: When an intention is verbalized, it specifies the performance to which the agent is committed in the future, or in which he is already engaged, and that performance may then be judged correct or mistaken in light of what is expressed.

So Anscombe is right to mark a difference here. Rather than standing in for performances in either a logical or developmental sense, expressions of intention have a force which no bit of natural behavior could have. Specifically, they make contradictable claims, and they require that something else one does then be regarded as correct or mistaken. Of course, we can sometimes see directly that someone is naturally barking up the wrong tree - say, merely running the brush along the wall when they mean to be painting the room yellow. But here it is important that we grasp a particular description of what they are doing or intending to do, one which a human being could give in answer to the question "Why?"53

To develop the implications of this, a number of contrasts, so far mainly implicit in our discussion, may now be made more explicit. The upshot is that a number of related features -contradictability, claiming, commitment, and the impunging of performances - can be seen to make intention fit for a notion of "expression" which lacks a non-linguistic counterpart.

1. Intentions are contradicted by other intentions. Midway through the book, Anscombe asks, "What is the contradictory of a description of one's own intentional action?" and she answers:

The contradiction of 'I'm replenishing the house water supply' is not 'You aren't, since there is a hole in the pipe', but 'Oh, no, you aren't' said by someone who thereupon sets out e.g., to make a hole in the pipe with a pick-axe. And similarly, if a person says 'I am going to bed at midnight', the contradiction of this is not: 'You won't, for you never keep such resolutions', but 'You won't, for I am going to stop you'. (p. 55)

To contradict an expression of intention is intentionally to oppose the act which the agent declares herself to be engaged in - i.e., what the agent is intent upon -- rather than to assess the agent's states, dispositions, or other conditions affecting the likeliness of performance. Verbal expressions of emotions and desires can also be contradicted of course, but what is denied, in that case, is the claim that the speaker has the item in question. Contradicting an agent's expression of intention to $\mathrm{V}$, in contrast, leaves no doubt - indeed, it presupposes - that she has the intention.

2. Like a belief, the expression of intention makes a claim upon the world. From (1), it follows that when Anscombe speaks of 'expression of intention' as something that can be true or false, this means a true or false claim about what one is doing or will do, not a good or a bad indication of one's state of mind. Herein lies the aspect of intention which leads some theorists to see it as a kind of belief. If an ordinary assertion ("The train just left") is one canonical form of the expression of belief, its contradiction is the denial of what is claimed ("No, it hasn't left yet"), not the denial that this expression manifests the speaker's state of mind. Expressions of 
both belief and intention make claims which can be countered by the denial that things are or will be as they are declared to be.

3. Yet, unlike a belief, the expression of intention can impugn what one does. Against this background, Anscombe distinguishes an expression of intention, not only in terms of the applicability of the question "Why?" (p. 90), but also, initially, in terms of the impugning of performances:

If I don't do what I said, what I said was not true. [...] But ... this falsehood does not necessarily impugn what I said. In some cases the facts are, so to speak, impugned for not being in accordance with the words, rather than vice versa. This is sometimes so when I change my mind; but another case of it occurs when, e.g., I write something other than I think I am writing: as Theophrastus says, the mistake here is one of performance, not of judgment." (pp. 4 - 5).

Putting this in terms of the previous point concerning contradiction, we may say: To contradict a prediction (or other expression of belief) is merely to deny a proposition of fact; to contradict an expression of intention is also to oppose what someone is doing or will do This specifies a discontinuity between expressions and mere behavioural 'indications' of intention. Anything which serves to indicate something (like the animal's intention to escape) will itself be the thing faulted or impugned when it fails to conform to what was putatively indicated. Where there is a clash between an indicator and what it purports to indicate, it is the indicator which stands to be corrected.

4. Practical knowledge: Expressions of intention are distinguished by the possibility of "mistakes in performance" and not otherwise by their "direction of fit." The last point touches on a larger theme of Anscombe's: No statement will count as an expression of intention unless it expresses "practical knowledge." If, for example, the speaker says "I'm going to crush the snail" (or "I am crushing the snail") on the basis of his observation of forces impelling him to move, then this is no expression of his intention. Now in speaking of expressions of intention as expressing practical knowledge, Anscombe might be taken to mean, in part, that the fit between such knowledge and what is known runs in the opposite direction than it does in cases of belief. This comes out when the speaker is not in fact doing what he takes himself to be doing. Here, if the speakers words are an expression of intention (rather than, e.g., a prediction), then the mistake will lie not in what the speaker thinks or says, but in what he is doing ("the mistake here is one of performance not of judgment"). ${ }^{54}$

Understandably, then, an enduring legacy of Anscombe's monograph is the idea of "direction of fit." The only disappointing aspect of this legacy is that the phrase "direction of fit" doesn't actually occur at its source -- and for good reason: While any talk of "knowledge" must find room for application of an idea of fit or accord, the fit present in cases of practical knowledge (or absent in cases of its failure) isn't simply a matter of reversing the priority between the same two items which figure in cases of speculative knowledge; practical knowledge involves a distinctive class of items known. Unsurprisingly, then, Anscombe's distinction bears little resemblance to the contemporary one between the functional roles of 
belief and desire, defined in terms of different directions of fit between such states and "the world." Instead of "two directions," Anscombe speaks of a difference between a mistake in what was said and a mistake in performance.

What turns on this? Three things:

(A) From expression of intention to desire. The "fit" which concerns Anscombe involves conformity between an expression of intention - something said - and what the person actually does. In the contemporary functionalist account, by contrast, the focus is no longer on verbal expressions, but on states of belief and desire, the later being defined by the requirement of the world (or "the facts") conforming to fit it rather than vice versa.

(B) From action to "the world". With this shift in focus from intentions to desires goes naturally a transformation in how the other side of the relation -- the world - is understood as well. When Anscombe speaks of "the facts [being]... impugned for not being in accordance with the words," the facts in question are someone's performance. But in the contemporary account, instead of a 'mistake in performance' -- an action characterized as needing correction -- we are referred to some state of the world itself (e.g., the absence of the cool drink I am longing for) that is to be altered, made to conform to the state of desire.

(C) Disappearance of the notion of "mistake". With the foregoing shifts in the nature of the relata (a person's state rather than his statements, this state's relation to some state of the world rather than to the person's actions), the idea of "mistake" or "correction" disappears from the analysis. For there is no mistake on anyone's part, mine or God's, when something I desire is out of reach; and the facts comprising this aspect of the world are in no way impugned by my desire or its expression. Rather, my having this desire simply means, other things being equal, that I will strive to alter these facts in order to satisfy my desire.

Given this, it is perhaps easy to see why the contemporary functional account of desire in terms of "direction of fit" between a person's state and the world -- does not appear in Anscombe, though it is widely attributed to her. Very simply, it is difficult to see how we are to apply normative notions to either item. In contrast, the application of "mistake" to actions and statements -- things done and said -- remains straightforward: These are the very things to which notions of mistake, correction, rightness, etc., primarily apply. ${ }^{55}$

5. Commitment. Various theorists have seen in intentions a form of "commitment," even though "I'm going to..." is not a performative utterance, and the relevant notion of commitment is different from promissory commitment. (Anscombe's denial that there are natural expressions of intention would be straightforward if expressions of intention were performatives, speech-acts dependent on conventional means). But although expressions of intention are not performatives, there is nonetheless a sense in which all intentions involve performances. For from (1) above to contradict an intention is to oppose an agent's action - it follows that an agent's expression of intention is itself a kind of engagement to act, not a mere revelation of his state of mind.

(Contradiction is symmetrical.) Self-contradiction in intentions exhibits the same pattern. If my intention to fly to Boston conflicts with my intention to stay home this weekend, this is not 
because these two intentions characterize my state of mind as one which dooms me to some frustration whatever happens (as happens with conflicting desires). It is rather that I engage myself in both doing and not-doing the same thing.

The way even pure intentions involve commitment is thus perhaps best understood in terms of the commisive aspect of action itself. Consider someone now engaged in writing the word "action." That is how someone who merely intends to write the word 'action' is also engaged: He stretches himself toward the act, awaits himself in its successful completion. ${ }^{56}$ The structure of intending to act, this is to say, is that of a performance, and, as such, something continuous with intentional action itself.

Of course, an intention for the future may be cancelled, blocked or otherwise never realized. Hence an objection arises here. What sort of 'commitment' is it which can be unilaterally rescinded by the agent, without penalty, simply by a change of mind? ${ }^{57}$ This argument proves too much, however. If it implies there is no sense of 'commitment' independent of obligation, it will follow that even someone now doing $\mathrm{X}$ - say, conducting a war in a foreign country -- hasn't committed themselves to anything. For this action may also be cancelled or blocked at any stage before its perfection. The completion of any extended action requires the agent's continuing assent; as Sartre puts it, there always remains the possibility of "putting [the] act into question." 58 So the fact that an agent may change his mind doesn't distinguish the commisive quality of pure intending from those paradigmatic commitments which are his temporally extended actions. Remembering the idea of spectrum at work here, we therefore affirm that a good analogue of 'intending' can be found in someone's doing something. ${ }^{59}$

Less metaphorically, the point is just that intention in a future action does not differ fundamentally from intention in (a present) action, or from intentional action. All alike, as Anscombe taught, are fit to be taken up in "expressions of intention," conceived as answers to the question "Why?" All alike are engagements of agency, and enter into the structure of commitment, contradiction, and impugning which characterizes performances as opposed to paradigmatic 'states.' All involve an agent stretching toward a describable future which is notyet. $^{60}$

To summarize: With the verbal expression of intention a discontinuity with natural manifestation arises, and it is this which Anscombe seeks to mark. Such expressions introduce something new: a characterization of what one is doing - what larger action one's actions are part of or toward which they are aimed. Expressions of intention are thus 'world-directed,' but not just in the way that expressions of states like belief or hope are: They make possible the application of the notion of "mistake" to performances, and they express practical commitments.

\section{Homage Revisited}

In conclusion, (1) three overlapping ways of making more precise the necessity of representing intention in terms of its verbal expression, and (2) a comment on one prominent theme. 
(1) First, it might be said that only verbal expressions of intention exhibit the responsiveness of the person to the special question 'Why." This question may apply to the bird pecking at the lime twig as much as to the man putting on his coat. The man, however, is in a position not only to answer the question, but also to refuse it application in a given formulation, as when he says that, as described in those terms, he was not aware he was doing that. (The bird is not expected to play any role in refusing application to the question 'Why?') Both acknowledging and refusing application of a certain question 'Why?' are part of the agent's understanding of his action as goal-directed. Refusing one application of the question makes the agent subject to some other application of it. ("If you weren't intentionally sawing the last plank of oak, then what were you doing? What did you take yourself to be doing?") The answer to such a question gives the terms in which the action is to be seen as intentional (the point of the activity, the good of it, what is being pursued). The role of the refusal of application to a particular 'Why?' question marks the fact that an action will have conditions of success or failure only as described in certain ways and not others. In answering this question, an expression of intention spells out the aim that some piece of behavior is guided by and to which the person is seeking to conform the rest of his action (i.e., the larger actions in Anscombe's ABCD structure). Aims have a linguistic structure in this sense, that the objects we handle in the world (and the movements we make in handling them) are multiply describable, and only a fraction of these descriptions will be relevant to what makes the results something aimed for.

Second, only when intention is not merely indicated, but verbalized as a statement of what one is doing, do we see how its expression could be something in light of which a performance might be mistaken or corrected. For only a statement - a claim upon the world established independently of the regularities it seeks to track -- could be in a position to impugn the facts. The content of an expression of intention will have to be conventionally or linguistically determined if it is to serve as an independent standard of this sort.

Finally, only a verbal expression of intention can directly display the unity of 'intention' as it occurs in 'intending to X' and "an intentional action.' For what is needed here is essentially the notion of expression we see at work in the description of what one is doing as, e.g., replenishing the water supply. When it comes to human actions, "the description of what we are interested in is a type of description that would not exist if our question 'Why?' did not." (p. 83)

Developing this formula, we might say: For every answer to the special 'Why?' question there is a complementary answer to a special question 'What?', applied to someone's performance. That is, because 'intentional' applies to action itself (and not just to something in the mental history of the agent causing action), a true and positive answer to the question 'Why?' tells us not merely why some event is taking place, but also what is happening, in terms of an action being performed. Thus, building on Anscombe's remark that there isn't "much to choose between [the answers] 'She is making tea' and 'She is putting on the kettle in order to make tea i.e., 'She is going to make tea'?," we might add: There often isn't much to choose between the questions "Why are you messing about with the kettle" and "What are you doing messing about with the kettle?" The answer to either question will be an expression of intention in the sense canvassed here in terms of the predicates of "contradictability," "commitment," "world- 
directedness," and "mistake in performance." That the concept of intention applies across the performative spectrum, on the one hand, and that the answer to the special question 'Why?' tells us also what is happening, amount here to the same thing. In action, the What appears together with - is already made for -- an answer to the question "Why?" This serves to distinguish action from other phenomena in nature, where the identification of What is to be explained is independent of how its interrogation in terms of 'Why?' may turn out. ${ }^{61}$

(2) Anachronistically put, Anscombe shows what is at best optional in the contemporary view that we understand what intention is only by asking what the mental state of intending is and how it could causally contribute to the production of intentional action. In place of this, she stresses the conceptual unity of a certain trinity: a single concept at work along a spectrum of cases, including 'pure' intending, intentions in action and intentional action. There is irony in the fact that one of her aims was to break up the sense of sharp distinctions among the divisions she is credited with having discerned. There is also a danger that recognition of this point will involve attributing to Anscombe the thesis that "intention" isn't a mental state at all, as happens in the behaviorist reading. But what Anscombe denies is only that we understand how to apply the notion of a "state" here, on the basis of its application in other contexts like those of belief and desire.

In fact, $T A$ inches toward the same conclusion, for its more recent discoveries might be represented like this: No psychology will afford the right materials for explaining action which does not make use of a concept which applies throughout the spectrum of unfolding action, i.e., which has the same internal complexity as action itself. Intuiting this, it becomes natural, within the framework of $T A$, to seek an enhanced psychology of states, one which might include such items as intending, planning or even believing or wanting in some special sense. No doubt, there are such states of mind, in the anodyne sense that human agents do intend, plan, want, etc. But the point to grasp is that leading one's sense of the psychological materials needed (for connecting the various uses of intention) is a prior understanding of what intentional action is. To make that understanding explicit was Anscombe's problem.

To elaborate, suppose the contemporary action theorist inspired, by the felt necessities of his material, to introduce a special psychological state called "intending" or "planning" (call it Xing: the name doesn't matter). His avowed task is to analyze it and to explain the behaviourinvolving uses of intention on the basis of their relation to it. But if X-ing is even to seem to be fit for this employment, it had better admit of internally nested relations (parts and wholes) of the sort exhibited in explanations like:

-- 'A is X-ing to Ø because he is V-ing' (A is planning to buy lumber because he is building a tree-house: the 'state' of X-ing explained in terms of a larger whole of action.) - 'A is X-ing to $\varnothing$ because he is $\mathrm{X}$-ing to $\Psi$ ' (A is planning to buy lumber because he is planning to build a tree-house: the 'state' of X-ing explained by reference to a different occurrence of $\mathrm{X}$-ing, one directed upon a wider description of the action.) 
- 'A is $\mathrm{V}$-ing because he is $\mathrm{X}$-ing to $\varnothing$ ' (A is getting his car keys because he is planning to buy lumber: an action explained by reference to the 'state' of $\mathrm{X}$-ing.)

The nature of the pressure to endow action theory with an enhanced psychology of states can be represented conscisely, in Anscombe's terms, like this: However we wish to understand the relevant action-theoretic state of X-ing, it ought to be the sort of thing about which it makes sense to ask 'why' (i.e., for what purpose) one is X-ing-to-do-something, and to answer this by reference to other things one is X-ing-to-do or other things one is doing. And of course the expression of this 'state' will have to partake of the structure of contradiction, actioncharacterization, and correction of performances (as identified through X-characterizing descriptions).

"Intending" and "planning," in idiomatic employments, do fit this special bill of requirements. But, as our discussion should make clear, that is because the basic psychological item needed must be: $\mathrm{X}$-ing to do something. That is, $\mathrm{X}$-ing, whatever it is, must inherit through its object (a performance), just the distinctive structure characteristic of intentional action. And as Anscombe's problem was just to make that basic structure explicit, this suggests a route by which $T A$ - after discoveries about the enhanced psychology of states it requires - might at length pay a more unqualified and accurate homage to Anscombe. 


\section{NOTES}

$1 \quad$ Or a "further intention in acting." These divisions play a structuring role in Anscombe's discussion. They explicitly appear at p. 1 (statement of the headings), p. 9 (the transition from "expression of intention" to "intentional action"), p. 40 (the unity of the three divisions), and p. 90 (return to "expression of intention for the future"). And they are drawn on elsewhere in Anscombe's discussion.

$2 \quad$ "Where we are tempted to speak of 'different senses' of a word which is clearly not equivocal, we may infer that we are in fact pretty much in the dark about the character of the concept which it represents." Intention, p. 1. In this essay, we approach Anscombe's ambitions in Intention in light of her sense of why the concept of "intention" calls for philosophy at all. The answer evidently refers to a submerged unity in our otherwise familiar employments of "intention." What makes these all cases of "intention" does not immediately appear.

3 Cf. Intention, p. 5.

$4 \quad$ On this distinction, see Richard Moran, 'Problems of Sincerity', Proceedings of the Aristotelian Society, Volume 105, pp. 341 - 361 (December 2005).

5 Or future statements of fact -- e.g., "Nurse will take you to the operating theatre": p 3.

6 With Anscombe's discussion of expression of intention vs. prediction, compare, e.g., Wittgenstein, Philosophical Investigations, p. 224.

7 This passage is obscure, even by Anscombian standards. The term "expression" is idiomatically multivalent enough to embrace Wittgenstein's talk of natural behaviour as "expressions" of intention. So it is hardly obvious that what Anscombe wishes to deny must be the same thing Wittgenstein is asserting. Further, Anscombe herself, turning to the question of "how...we tell someone's intentions," will point out that intentions are often legible in someone's behavior: "You will have a strong chance of success [at this] if you mention what he actually did or is doing." (p. 7-8) This only makes more pressing the question of what could be stake in her denial that natural behavioural manifestations of intentions are proper "expressions" of it. See $\S \S \mathrm{V}$-VI below.

8 Donald Davidson, “Introduction,” Essays on Actions and Events (Oxford, 1985), p. xiii.

9 Michael Bratman, Intention, Plans and Practical Reason, pp. 1, 3, 5 and n. 1. Cf. H. L. A. Hart, "Intention and Punishment," in Punishment and Responsibility (New York: Oxford University Press), p. 117: "Intention is to be divided into three related parts...The first I shall call "intentionally doing something'; the second "doing something with a further intention," and the third "bare intention" because it is the case of intending to do something in the future without doing anything to execute this intention now."

10 "Reluctantly": Cf. Davidson, "Intending" in Essays on Actions and Events, p. 88. But if reasons, conceived as belief/desire pairs, seem adequate to explaining what it is to act intentionally, they appear immediately hopeless when it comes to "intending to act." One main problem is that the familiar conflicts which are present among an agent's desires seem intolerable when it comes to her intentions; intentions seem to "commit" the agent in a way which mere desires do not. This and other difficulties with belief/desire psychology in the theory of intention are discussed by Bratman in Intention, Plans and Practical Reason, ibid. On the apparently commissive aspect of "intending," see Bratman's discussion at pp. 4-5, and our discussion infra, §VI.

Davidson's reluctance, as opposed to Bratman's boldness, will comprise only a superficial difference here. For the reluctance is only about recognizing "intention" as a sui generis state of mind (one not "ontologically reducible" to beliefs and desires: see Davidson "Intending," p. 88, 83). Both take for granted, however, the explanatory framework described in this section

$11 \quad$ See infra, pp. 
We shall generally use "intending" or "intention to act" for this category.

13 "It would be astonishing if that extra element were foreign to our understanding of intentional action." Davidson, Intending, p. 88; and see p. 89: "[T] here is no reason not to allow that intention of exactly the same kind is also present when the intended action eventuates."

14 See Davidson, Essays on Actions and Events p. xiii, and “Intending," pp 87-88.

15 See Bratman, op. cit., pp. 5-6. Anscombe says almost nothing in Intention about whether action explanations mention causes, save for an occasional suggestion that the relevant notions of "a cause," and "causal" would have to be made clearer for us to understand what this question is about. See e.g., $\S \S 5,9-11$.

16 Bratman, Intention, Plans and Practical Reason, p. 7 (p. 5 check?).

$17 \quad$ Nor can we understand this on the basis of the agent's having done something for a such a reason (say bought a ticket); for, by hypothesis, the intention in question may remain pure, the action merely proposed.

18 Cf. Intention, p. 84: “[T]he term 'intentional' has reference to a form of description of events" (Anscombe's emphasis).

19 One feature of this analogy seems worth highlighting. Someone who, endeavoring to understand "wrongful," started with the case in which it characterizes an agent's plan would find themselves having to connect this to other cases through a story about such a plan bringing about -"in the right way" of course - a situation in which a different, world-involving notion of wrongful finds application (e.g., to another's loss or injury). (And they might feel puzzled over how applications of the world-involving notion of "wrongful" - e.g., wrongful injury - could involve a greater degree of culpability, given the fortuitous role which factors beyond the agents control are bound to play in this extended story; but this is a distinguishable problem.) Starting at the other end, one sees what makes a plan wrongful by seeing what happens when it succeeds. This doesn't occlude the possibility of causal explanations, but it suggests that the unity of the divisions can and perhaps must be grasped before they get under way.

20 See Ludwig Wittgenstein, Philosophical Investigations $§ \S 629-660$ (esp. 635, 645-46), pp. 216-17; Zettel 44. Anscombe alludes to this discussion on p. 6 of Intention.

21 For a related discussion, see Anscombe, "Events in the Mind" in Metaphysics and the Philosophy of Mind: Collected Papers Volume II, esp. pp. 57-61.

22 Cf. Intention, p. 77 on the absurdity of accepting both the empiricist idea of pleasure as an impression of some kind and seeing it as "quite generally the point of doing anything". Anscombe is adapting Investigations §218: "Meaning is not a process which accompanies a word. For no process could have the consequences of meaning."

23 Cf. Intention, p. 92: "Nor can we say: But in the expression of intention one isn't saying anything is going to happen! Otherwise, when I had said 'I'm just going to get up', it would be unreasonable later to ask 'Why didn't you get up?'. I could reply: 'I wasn't talking about a future happening, so why do you mention such irrelevancies?' On Anscombe's account, an expression of intention differs from a prediction in not being founded for the speaker on evidence or observation, as well as in the particular notion of "mistakeness" we apply in connection with it.

24 "Direct": i.e., knowledge not merely on the basis of an inference from how it is with the speaker. Cf. Intention, p. 3: "[N]or does the patient normally infer the information from the fact that the doctor said that; he would say that the doctor told him." 
25 See Michael Thompson, "Naive Action Theory," [cite]. Our presentation of the spectrum of intention owes a quite general debt to Thompson's paper.

26 On the contrast between states and performances (and taking time vs. going on for a time), see A. Kenny, Action, Emotion and Will (London, 1963), Ch. 8, to which we are indebted here.

27 The use of intention which arises in considering how to understand a speaker (especially when the speaker is absent, e.g., -- "the author's intention") would appear to call for separate treatment, as it does not involve a notion of unfolding action. In light of this case, it appears that Anscombe's divisions are neither exclusive nor exhaustive.

28 Anscombe is exploring here the disabling consequences of isolating one her divisions - intentional action -from the others. However, her overall point is more general: Other distortions would arise from the isolation of any of the divisions.

29 See J.L. Austin, 'A Plea For Excuses', in Philosophical Papers, ed. J. O. Urmson and G. J. Warnock (Oxford, Clarendon, 1961).

30 Thus, someone writing the word "action" may have a pure intention, at this moment, to write the letter "c." But asking why they intend to write "c" will disclose this intention to be grounded in an action already underway: the pure intention to write "c" stands to writing the word "action" (once they have begun on the "a") as writing the word "action" does to writing the sentence "An intention can exist..." and so on. So pure intentions are everywhere. But that is because actions, underway but not yet completed, are everywhere; such actions are their grounds

31 Michael Thompson, "Naive Action Theory" [cite]

32 Thompson, "Naive Action Theory"

33 Michael Bratman's master term - planning - fits the bill of particulars here. Unlike beliefs and (appetitive) desires, plans are wholes which rationalize their subparts, can be pure or impure, take a performance from as their object ("I plan to Ø"), are subject to the question "why" in the relevant sense ("for what purpose?"), can be commanded ("Plan to be there at 4:00!"), and so on. Planning, in short, shares in the structure of action. Nothing this wasn't true of would even seem to be a good candidate for an intention-explaining psychological state.

34 The instructive exception to this is the right-limit case, which, by definition, does not express imperfection and hence does not enter into action-explanation: E.g., in answer to "Why?," never the past-perfect (I Ø-ed), but only the past progressive (I was Ø-ing).

35 See the previous discussion above, $\mathrm{p}$.

36 This is sometimes missed because there is no imperative-form ("Intend to Ø!"). However, nothing is easier than making someone's intention - e.g., to return the book - the object of a command: One simply orders them to return the book. It might be objected that were intending really an etiolated form of performance, it ought to be possible to command someone to "intend to return the book" in perfect purity, i.e., "Plan to return the book, but don't actually return it!" But the answer to this is that it is also impossible to command someone < to go ahead with returning the book without actually returning it.> Intending to $\varnothing$ stands to the progressive $\varnothing$-ing just as Ø-ing (or doing things in order to Ø) stands to successfully Ø-ing or having Ø-ed: None can be commanded apart from the others.

37 The italics are our notes.

38 The relevant sense of the question "Why," and the fact that positive answers to it are themselves expressions of intention, are mutually defining notions for Anscombe. 
Cf. Intention, p. 80: Like Aristotle's "practical reasoning," the "order of questions 'Why'? can be looked at as a device which reveals the order" in the diverse materials of action. But Anscombe also points out: It is "as artificial as Aristotle's [construction]; for a series of questions 'Why?'... with the appropriate answers, cannot occur very often."

$40 \quad$ Wittgenstein, Philosophical Investigations, $\$ 647$

41 This point appears twice in Intention: pp. 5, 86-87.

42 Cf. p. 8: "[I]f you want to say at least some true things about a man's intentions, you will have a strong chance of success if you mention what he actually did or is doing." If intentions were not so legible, their personal expression would lack much of its point. Such expression gives another warrant to expect behavior of a certain describable shape, and this implies a general capacity to recognize another's behavior, when the time comes, as satisfying (or frustrating) those expectations.

43 See, e.g., Stuart Hampshire, Thought and Action, pp. 97-98. Relatedly, it is sometimes said that only linguistic creatures initiate action by deciding on it from among a range of alternatives. And, no doubt, we speak of "decisions," just where someone has, in effect, answered a question, or resolved their intentions against the background of other prospects. But these points are moot here, for the reasons explained in the text.

44 Davidson, "Thought and Talk" in Truth and Interpretation, p. 63.

45 Indeed, Michael Tomasello's reading of the empirical research on non-human primates defends just this position: While brutes have intentions, they fail to recognize intentions - and hence to distinguish ends from means, and both from the upshots of what is done -- in others. See The Cultural Origins of Human Cognition, Harvard University Press, 2001.

46 Anscombe, "Under a Description" in Metaphysics and the Philosophy of Mind, pp. 208-219. This is in further explanation of her remark in Intention, pp 86-87: "[W]e certainly ascribe intention to animals. The reason is that we describe what they do in a manner perfectly characteristic of the use of intention concepts: we describe what further they are doing in doing something..... We do this although the cat can utter no thoughts, and cannot give expression to any knowledge of its own action, or to any intentions either."

47 This is just what is happening, according to Donald Gustafson, one of the few commentators to notice the problem. Concerned mainly to defend Wittgenstein, Gustafson criticizes Anscombe for overlooking this: "[T]hat a person's face has a determined look, while it does not imply that he expressed determination in the sense that his saying he is determined does so, is [nonetheless] an expression of determination or a determined expression" The implication must be that $A P$ joins no issue, since the impersonal sense in which Wittgenstein is asserting that the stalking cat expresses an intention isn't the personal sense in which Anscombe would be denying it. This resolution comes at the cost of making Anscombe incoherent, however. For if her point were merely that animals don't express their intentions in the personal sense -- i.e., don't tell us of them -- then she ought to have said the reverse of what she does: Intention is just like emotion in this respect, for animals don't tell us of their emotions, or of their hopes and fears, either.

48 In point of fact, ordinary usage gives $A P$ some support. One can express one's intention to turn right by making a hand gesture (since this is a "bodily movement with a conventional meaning": p. 5); but someone who begins to turn right is not "expressing an intention" to do so, even though that same movement might express his determination or his fear, and even though it may make his intentions (e.g., to turn right, to confuse the enemy, etc.) apparent to an observer. We need to see more clearly, however, what distinction language is harboring here.

49 Of course, numerous states of the person - e.g., a dulling throbbing in one's right knee, a slow, spreading 
fear in the pit of one's stomach - are manifested only in creatures who have the linguistic means to differentiate and report them. So conventional expression goes beyond natural expression. But the present point isn't that conventional expression only deputizes for what is already expressible by non-verbal behaviour, only that it sometimes does.

$50 \quad$ Cf. Wittgenstein, Philosophical Investigations, p. 189.

51 Cf. Ludwig Wittgenstein, Philosophical Investigations $§ 242$, Zettel $§ 545$.

52 See Wittgenstein, Remarks on the Philosophy of Psychology, volume II, § 179: "There is no cry of intention" -- i.e., as there is a cry of pain, joy, grief, etc.

53 Even God's intentions, in so far as they are not expressed but merely revealed by history, do not impugn anything. For example, the regularity of the seasons does not afford a basis - as a verbal expression would -- for regarding unseasonable rain as a divine mistake. See Anscombe, "Rule, Rights and Promises," in Ethics, Religion and Politics: Collected Philosophical Papers Vol. III (Blackwell, 1981), p. 99: "God himself can make no promises to man except in a human language."

The point of Anscombe's denying that an incipient course of action expresses intention (as a face or tone of voice expresses anger) might be approached another way, by considering what might serve to distinguish impersonal "expressions" from other signs or indications of a person's state. As Anscombe elsewhere remarks, "A man could be said not to have given expression to his anger at all — he merely brought it about that the man who had offended him was ruined or hanged." "Pretending" in Metaphysics and the Philosophy of Mind: Collected Philosophical Papers, Vo. II (University of Minnesota Press, 1981), p. 88. According to this, an expression is not a mere sign or indication, but what exactly is the difference? It seems correct to say: An expression allows for the possibility of retaining the concept in cases where what is expressed is absent; a mere sign or indication does not. Thus, we may say that the relation "X expresses Y" excludes cases in which the truth of the statement depends on the truth or actuality of Y. To illustrate: Ruining him is not an expression of anger, for it is not anger which is expressed at all unless the person really is angry. In contrast, if $\mathrm{X}$ expresses $\mathrm{Y}$, then $\mathrm{Y}$ is itself present in the expression $\mathrm{X}$, as e.g., anger is present in the angry furrows in the face, whatever the person's state of mind. Hence it is possible to be surprised that (e.g.) a face expresses anger (e.g., since this person has no cause for complaint), whereas - since a person's action only manifests an intention to do what they are really doing or intending to do -- there can't be any surprise that a bit of behavior manifests an intention to do such-and-such. Considered apart from their verbal expressability, intentions are sunk in facticity. This is why Anscombe suggests an analogy between the movements of the cat (as a basis for attributing intentions) and the car's stalling engine. Just as the engines behavior indicates that the car is going to stop only if the car is going to stop, so the movements of the cat indicate only what it actually goes on to do.

$54 \quad$ For more on the notion of practical knowledge, see Richard Moran, "Anscombe on 'Practical Knowledge"', in Agency and Action, eds. J. Hyman \& H. Steward, Cambridge: Cambridge University Press, 2004, pp. 43-68 (Royal Institute of Philosophy Supplement: 55).

55 The source of the phrase 'direction of fit' as attributed to Anscombe seems to be Mark Platts, Ways of Meaning (Routledge, 1979), pp. 256-7. The transformation of her idea is already complete in this short passage, which re-writes her original thought about the relation between an expression of intention and what the person does as a claim about the relation between a state (desire) and the world: "Miss Anscombe, in her work on intention, has drawn a broad distinction between two kinds of mental state, factual belief being the prime exemplar of one kind and desire a prime exemplar of the other (Anscombe, Intention, $\S 2$ ). The distinction is in terms of the direction of fit of mental states with the world."

56 See Luca Ferrero, "Intending and Doing" (manuscript), which stresses the active quality of such "waiting" (monitoring for interferences, commitment of resources, etc) in the usual case. 
See Donald Davidson, "Intending" in Essays on Actions and Events, p. 90.

58 See the opening quotation from Sartre, Being and Nothingness, p. 74.

59 Or better, their "being engaged in doing something": the word "engaged" straddles the sense of (1) doing something and (2) being committed - in a non-promissory sense - to doing something.

60 We agree with Ferrero's conclusion (note 51 above) that intending is a kind of performance which is continuous in structure with intentional action, so that that to intend to $\Phi$ to is be (already) engaged in $\Phi$-ing. As Ferrero puts it, "[F]uture directed intending is not a truly separate phenomenon from either the intending in action or the acting itself. Ultimately, all intentions are in action, or better still, in extended courses of action."

61 In this connection, see recent work of Pamela Hieronymi, where actions as well as attitudes are not only understood as embodying reasons, but more specifically where the relevant notion of 'reason' is the more articulated one of "a consideration that bears on a question", as distinct from the more primitive one of "a consideration in favor of" (which might apply equally to considerations in favor of having some belief as well as to considerations in favor of its truth). In "The Wrong Kind of Reason," The Journal of Philosophy 102, no. 9 (September 2005): 437-57; and "Controlling Attitudes," Pacific Philosophical Quarterly 87, no. 1 (March 2006): 45-74, the appeal to the applicability of a certain range of questions as constituting the action or the attitude is motivated in part by reference to Anscombe's 'Why?' question. 